\title{
A dose-response meta-analysis between serum concentration of 25-hydroxy vitamin $D$ and risk of type 1 diabetes mellitus
}

\author{
Yilin $\mathrm{Hou}^{1,2} \cdot$ An Song $^{3} \cdot$ Yuxin $\mathrm{Jin}^{1,2} \cdot$ Qiuyang $\mathrm{Xia}^{1,2} \cdot$ Guangyao Song $\mathbb{(}^{1,2} \cdot$ Xiaoping Xing $\mathbb{(}^{3}$
}

Received: 23 April 2020 / Revised: 23 September 2020 / Accepted: 10 November 2020 / Published online: 24 November 2020

(c) The Author(s) 2020. This article is published with open access

\begin{abstract}
It remains debatable whether vitamin D plays any role as a risk factor for type 1 diabetes mellitus (T1DM). We have summarized the effect of circulating 25-hydroxy vitamin $\mathrm{D}[25(\mathrm{OH}) \mathrm{D}]$ concentration on the risk of developing T1DM via a dose-response meta-analysis. We undertook a database search on PubMed, Embase, and Cochrane Library from inception to January 2020. A meta-analysis based on random-effects model was applied. Subgroup analysis and meta-regression were performed to inspect the source of heterogeneity. Dose-response data were examined using the generalized least squares trend estimation method. This study was registered with the PROSPERO (ID: CRD42020166174). In total, 16 studies including 10,605 participants (3913 case patients) were included. The pooled odds ratios (OR) and $95 \%$ confidence intervals $(95 \% \mathrm{CI})$ for the highest versus the lowest $25(\mathrm{OH}) \mathrm{D}$ concentration was $0.39(0.27,0.57)$, with a high heterogeneity $\left(I^{2}=76.7 \%, P<0.001\right)$. Meta-regression analysis identified latitude $(P=0.02)$, adjustment for gender $(P=0.001)$, and 25 $(\mathrm{OH}) \mathrm{D}$ stratification $(P<0.001)$ as sources of heterogeneity. Furthermore, the nonlinear dose-response analysis determined the OR $(95 \% \mathrm{CI})$ of T1DM to be $0.91(0.90,0.93)$ per $10 \mathrm{nmol} / \mathrm{L}$ increase in the $25(\mathrm{OH}) \mathrm{D}$ concentration. A ' $U$ '-shaped association was found between serum $25(\mathrm{OH}) \mathrm{D}$ concentration and risk of T1DM. The present study highlights the significant inverse association between the circulating 25(OH)D concentration and the risk of T1DM.
\end{abstract}

Keywords Type 1 diabetes $\cdot$ Insulin-dependent diabetes $\cdot$ Vitamin D $\cdot 25$-hydroxy vitamin D $\cdot$ Meta-analysis Dose response

These authors contributed equally: Yilin Hou, An Song

Supplementary information The online version of this article (https:// doi.org/10.1038/s41430-020-00813-1) contains supplementary material, which is available to authorized users.

Guangyao Song sguangyao2@163.com

$\triangle$ Xiaoping Xing xingxp2006@126.com

1 Department of Internal Medicine, Hebei Medical University, Shijiazhuang 050017 Hebei, PR China

2 Endocrinology Department, Hebei General Hospital, Shijiazhuang 050051 Hebei, PR China

3 Key Laboratory of Endocrinology, Ministry of Health, Department of Endocrinology, Peking Union Medical College Hospital, Peking Union Medical College, Chinese Academy of Medical Sciences, 100730 Beijing, PR China

\section{Introduction}

Type 1 diabetes mellitus (T1DM) is an insulin-dependent diabetes that is characterized by immune-mediated destruction of pancreatic $\beta$ cells, which leads to severe insulin deficiency [1]. The incidence of T1DM was 22.3/ 100,000 persons in the USA in 2014-2015, which has nearly doubled among the youth (aged $<20$ years) in the past decade [2]. A pooled analysis across 26 European centers recorded a 3.4\%/annum increase in the incidence rate [3]. However, the estimated incidence of T1DM for individuals across ages is $1.01 / 100,000$ persons in China [4]. It is believed that factors, such as obesity, breastfeeding, maternal and perinatal factors, virus infection, omega-3 fatty acid status, and serum $25(\mathrm{OH}) \mathrm{D}$ concentration play crucial roles in the prevention regimen of T1DM [1]. Reportedly, the number of patients with T1DM presenting with insufficient serum $25(\mathrm{OH}) \mathrm{D}$ concentration is growing rapidly [5].

The concentration of 25-hydroxy vitamin D [25(OH)D] in the serum reflects the status of vitamin D in the blood circulation [6]. Vitamin D deficiency has been identified 
to be common among patients with T1DM [5]. This secosteroid hormone is mainly produced from the precursor protein 7-dehydrocholesterol in the skin when exposed to solar ultraviolet $\mathrm{B}$ radiation and acquired slightly from the diet. The 25-hydroxylase enzyme in the liver transforms vitamin $\mathrm{D}$ to an intermediate inactive form of this vitamin, $25(\mathrm{OH}) \mathrm{D}$, which is then transformed to the active form 1,25 -hydroxy vitamin $\mathrm{D}$ by $1 \alpha$-hydroxylase enzyme in the kidney [7]. As vitamin D regulates the immune system and autoimmunity, it may serve as a potential protective factor in the development of T1DM [1]. The effects of vitamin $\mathrm{D}$ on non-skeleton disorder remains debatable. Moreover, the role of serum 25(OH)D concentration in the risk of T1DM remains controversial $[1,7]$. A birth-cohort study [8] in Finland suggested that sufficient vitamin D supplementation could assist in decreasing T1DM risk. A cross-sectional study [9] revealed that $70 \%$ of children with T1DM had vitamin $\mathrm{D}$ deficiency. The TEDDY study [10] reported that higher childhood $25(\mathrm{OH}) \mathrm{D}$ concentration is associated with lower islet autoimmunity, while prospective studies, such as DAISY and DIPP [11, 12] reported no such association between vitamin D intake or $25(\mathrm{OH}) \mathrm{D}$ concentration in the childhood and the risk of islet autoimmunity or T1DM. Moreover, vitamin D supplementation plays a protective role in hyperglycemia, while training anaerobically, and, in hypoglycemia, while training aerobically [13].

Several recent observational studies examined the relation between the serum $25(\mathrm{OH}) \mathrm{D}$ concentration and the risk of T1DM. Accordingly, we undertook the present meta-analysis to investigate the correlation between the serum 25(OH)D concentration and the risk of T1DM, while demonstrating their dose-response association.

\section{Methods}

\section{Protocol and registration}

This study was registered with the PROSPERO (ID: CRD42020166174).

\section{Search strategy and selection studies}

The databases of PubMed, Embase, and Cochrane Library were searched for literatures published from inception to January 2020. Free-text terms and MeSH terms were used as follows: "type 1 diabetes" OR "type I diabetes" OR "insulindependent diabetes" OR "juvenile onset diabetes" OR "sudden onset diabetes" OR "autoimmune diabetes" OR "brittle diabetes" OR "Ketosis Prone diabetes" AND "vitamin D” OR “25-hydroxy vitamin D" OR “25(OH)D” OR "1,25-dihydroxy vitamin D" OR "1,25(OH)2D" OR "calcitriol" OR "calcidiol". Potentially eligible studies were included without placing any language restriction in the search.

The following inclusion criteria were set to select clinical studies for the present meta-analysis: (1) Observational studies on humans, except for cross-sectional studies; (2) All subjects met the diagnosis criteria of T1DM; (3) The serum $25(\mathrm{OH}) \mathrm{D}$ concentration was measured quantitatively; (4) Studies that evaluated the association between the 25 $(\mathrm{OH}) \mathrm{D}$ concentration and the risk of T1DM and were obliged to report the odds ratios (OR), relative risk or hazard ratios with the corresponding $95 \%$ confidence intervals $(95 \% \mathrm{CI})$ or useful data for these statistics. All reviews, case reports, letters, registration of trials, and conference abstracts without full-text link were excluded from the study.

\section{Data extraction and quality assessment}

All literatures collected according to the search strategy were independently assessed by two authors (YH and YJ), who were blinded to author and journal details, to identify potentially eligible studies. Any issue that presented was addressed by discussion with the third author, GS. The literature selection method flowchart is illustrated in Fig. 1. The following data were extracted from the included studies: the name of the first author, publication year, study design, geographical locations (based on latitude search on Google Maps), age, gender, body mass index, risk of T1DM, serum 25(OH)D concentration, and assay method for $25(\mathrm{OH}) \mathrm{D}$ concentration estimation. Quality assessment was gauged with reference to the Newcastle-Ottawa Scale for cohort and case-control studies [14]. A score of 4-6 was considered moderate quality and that of 7-9 as high quality.

\section{Statistical analysis}

OR and $95 \%$ CI were obtained as the summary risk estimates for T1DM from all studies, and the relative risks and the hazard ratios were esteemed to be equivalent to OR. Heterogeneity among the studies was estimated by Cochrane Q test and $I^{2}$ statistic, which was confirmed to be statistically significant at $P<0.05$ and $I^{2}>50 \%$. Pooled OR and $95 \% \mathrm{CI}$ were evaluated using the random-effects model (DerSimonian and Laird method) [15]. To scrutinize the potential source of heterogeneity, manifold subgroup analysis ranging from latitude of geographical locations, serum $25(\mathrm{OH}) \mathrm{D}$ concentration, and assay method for estimating the $25(\mathrm{OH}) \mathrm{D}$ concentration were performed. Heterogeneity between the subgroups was measured by meta-regression analysis. At $P<0.05$ for meta-regression, the heterogeneity 
Fig. 1 The flow diagram of literature research and study selection.

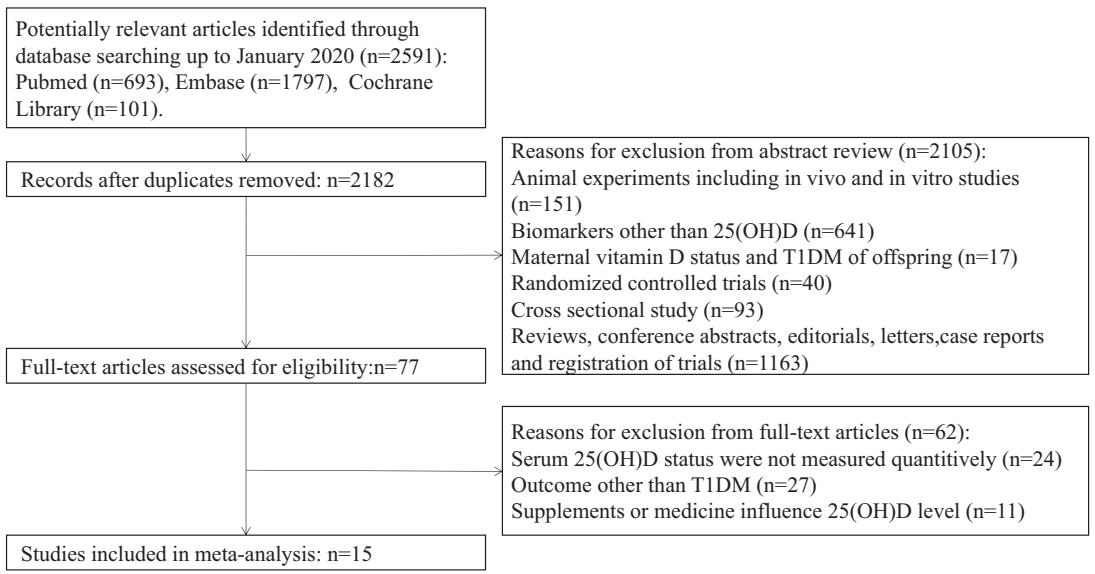

between the subgroups was considered to be significant [16]. By omitting one study at a time, we conducted a sensitivity analysis to test for the robustness of the pooled results. Forest plots were applied to describe the summary effects. Publication bias was separately assessed via funnel plot and Egger's test. The funnel plot was asymmetrical or the $P<0.10$ was for Egger's test, indicating potential publication bias [17]. In addition, the overall effects were estimated by the trim and fill method after adjusting for the missing studies [15, 18].

Based on the dissimilar cut-off points for categories in individual article, we computed OR and 95\% CI of T1DM for every $10 \mathrm{nmol} / \mathrm{L}$ of serum $25(\mathrm{OH}) \mathrm{D}$ concentration increase via generalized least squares for trend estimation, as suggested by Greenland and Longnecker [19] and Orsini [20]. The mean concentration of the serum 25(OH)D concentration in each category was considered as the corresponding dose. If the boundary of the highest category was open ended, the midpoint of this category was set at the lower boundary, multiplied by 1.5. If the lowest category was unavailable, we set it as zero. The 25(OH)D concentration and T1DM risk for each distribution of cases and controls were distilled as per the method. In this dose-response analysis, we excluded studies that did not quantify the number of cases and controls per category as well as those that reported 25 $(\mathrm{OH}) \mathrm{D}$ concentration with $\mathrm{OR}$ and $95 \% \mathrm{CI}$ for less than 3 categories.

In addition, we appraised a potential curve for dose-response relationship between the $25(\mathrm{OH}) \mathrm{D}$ concentration and the summary OR and 95\% CI for T1DM. A restricted cubic spline model with four knots at the 5th, 35 th, 65th, and 95th percentiles of $25(\mathrm{OH}) \mathrm{D}$ concentration was used. The linear and nonlinear models were calculated by testing the null hypothesis, with the splines coefficient considered zero.

All statistical analyses were performed using the Stata version 15.1.614 (Stata Corp, Texas, USA).

\section{Results}

\section{Literature research and study characteristics}

Based on our initial literature research, 2591 articles were identified, of which 409 that were identified to be duplicates and 2105 that were uncorrelated, were removed. After the full-text screening, 62 articles were excluded as they did not meet all of the eligible criteria listed in Fig. 1. Finally, 12 case-control studies [21-32], two nested case-control studies [33, 34], one case-cohort study [28], and one cross-sectional case-control study [35] were pooled in the meta-analysis.

The characteristics of each included studies are outlined in Table 1. Briefly, 10,605 subjects with 3913 T1DM cases and 6692 healthy controls participated in the 16 studies. The geographical locations of all the study areas were based in the Northern Hemisphere. With respect to the age groups, 12 studies were conducted among children [21, 22, 2429, 31, 32, 35], two in adults [33, 34], and two in a blended population of children and young adults [23, 30]. Gorham et al. [33] and Munger et al. [34] conducted their studies among military service members of the United States. When assessed with reference to the Newcastle-Ottawa Scale, five studies [25-28, 31] showed a moderate quality score and 11 [21-24, 28-30, 32-35] showed a high-quality score. The characteristics of the serum $25(\mathrm{OH}) \mathrm{D}$ concentration and the risk of T1DM are detailed in Table 2. The OR and 95\% CI were classified by each category of $25(\mathrm{OH}) \mathrm{D}$ concentration from 5.14 to $250 \mathrm{nmol} / \mathrm{L}$. Various assay methods were applied to quantify the $25(\mathrm{OH}) \mathrm{D}$ concentration. Most matched or adjustment variables were identified to be age, gender, and ethnic traits. The duration of T1DM ranged from being newly diagnosed to having been diagnosed for several years.

\section{Meta-analysis}

The forest plot for the pooled effects of the highest versus the lowest cut-off point of $25(\mathrm{OH}) \mathrm{D}$ concentration on the 


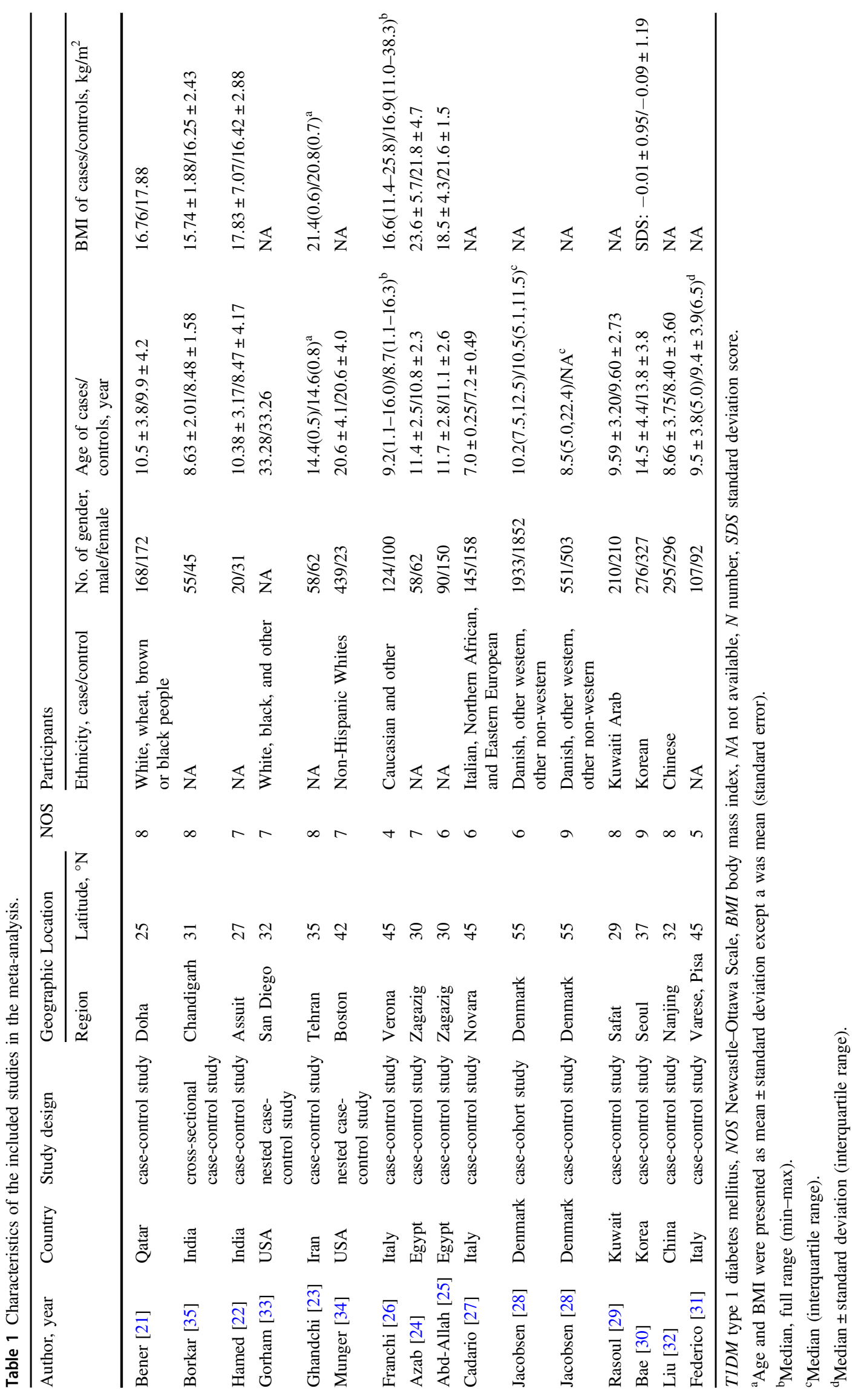




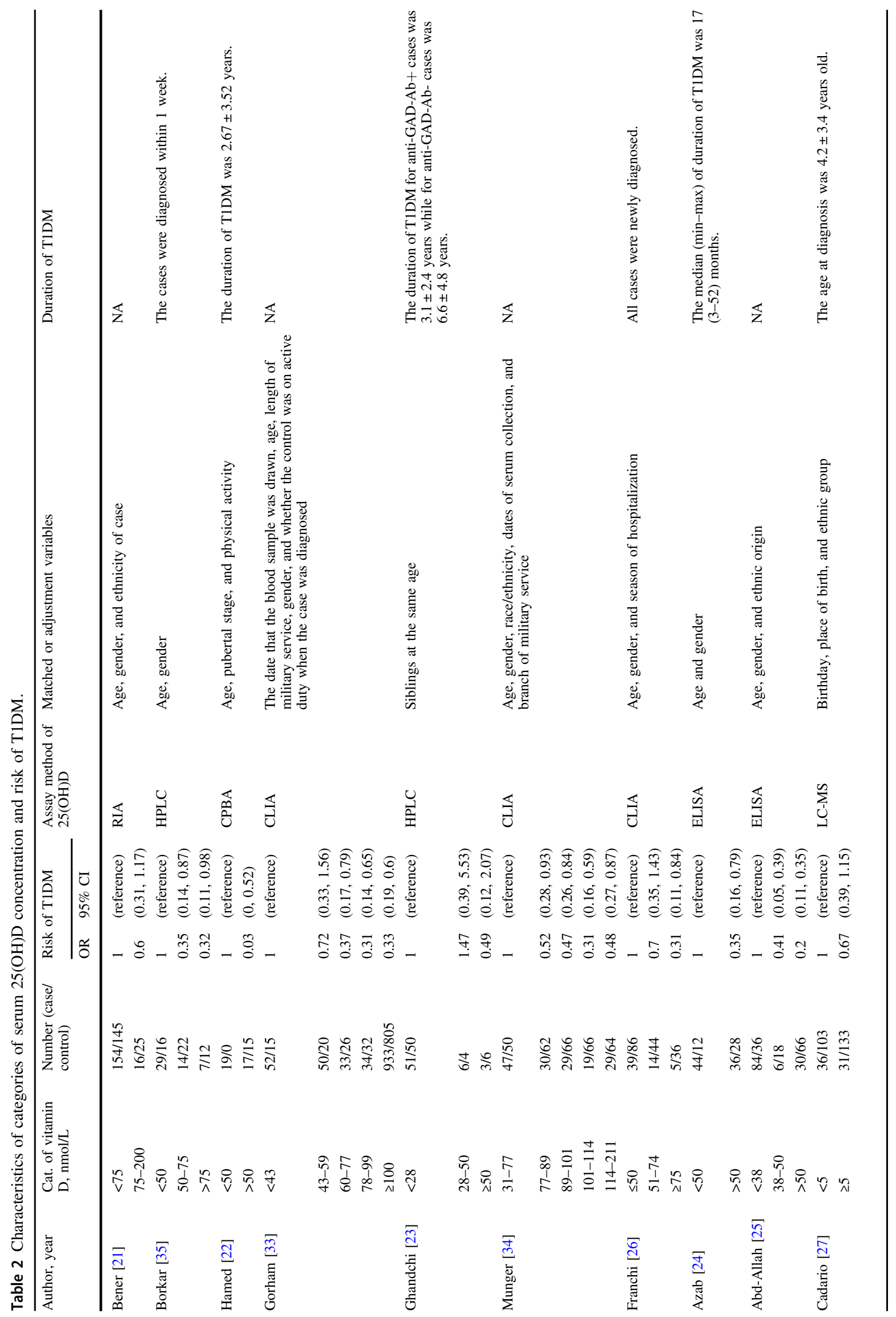




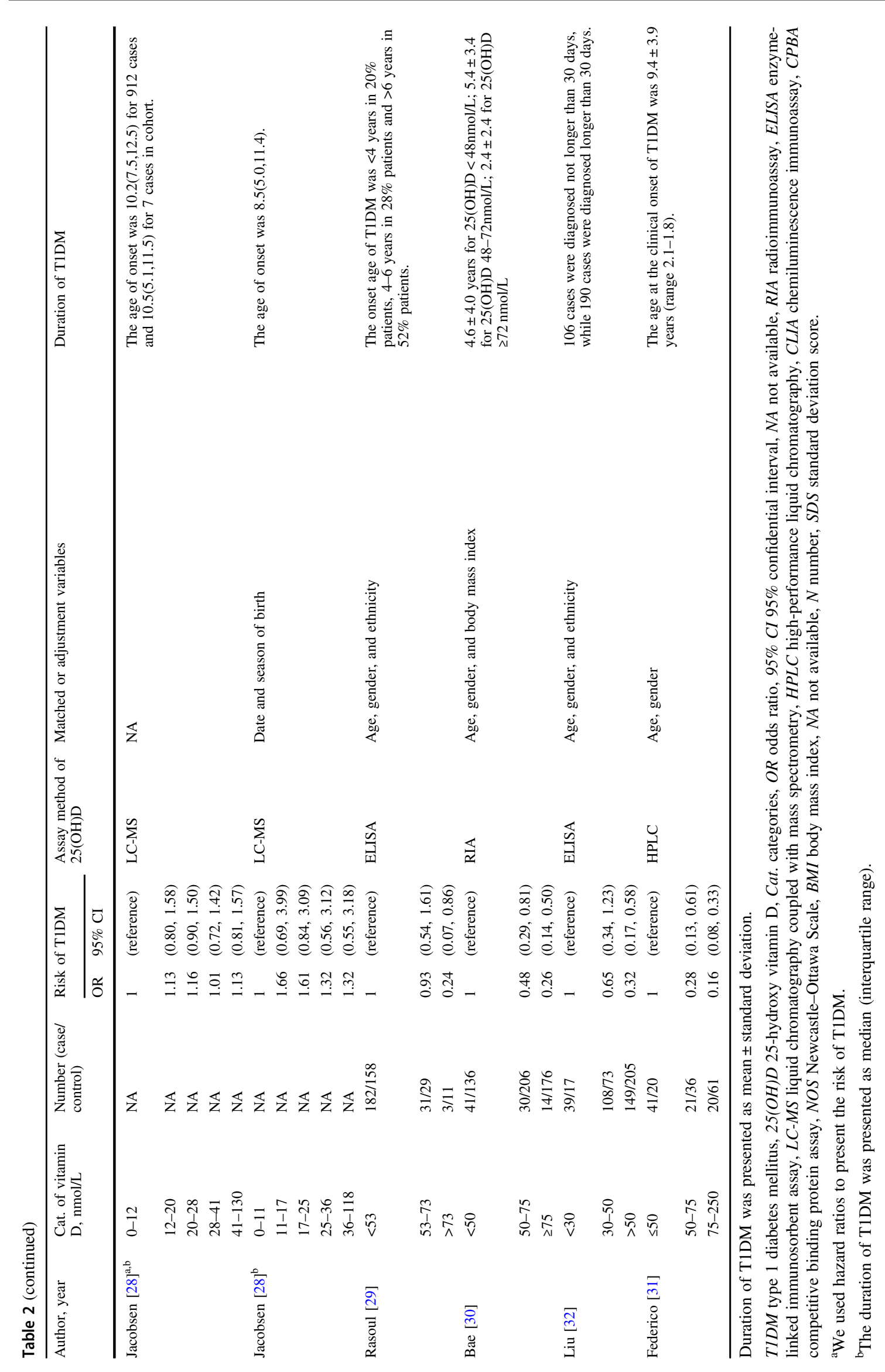


Fig. 2 Forest plot for pooled effects of serum $25(\mathrm{OH}) \mathrm{D}$ concentration on risk of T1DM.

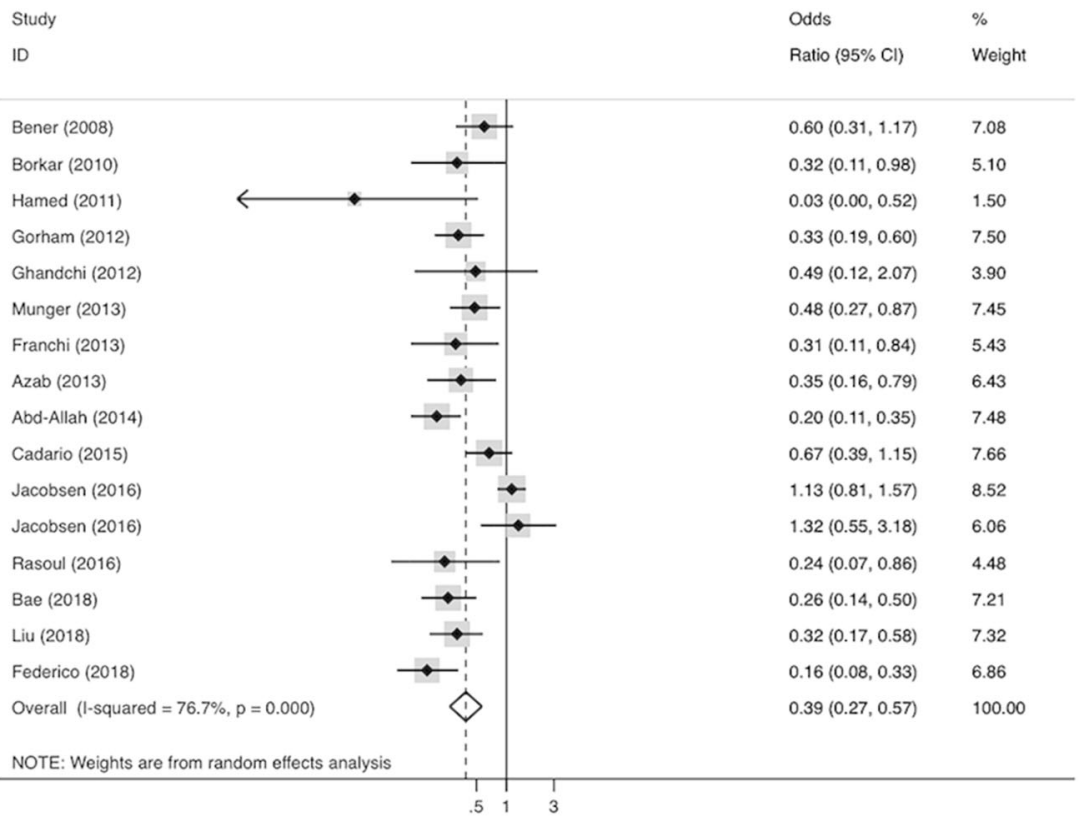

risk of T1DM is illustrated in Fig. 2. The case-cohort study and the case-control study examined by Jacobsen et al. [28] did not provide eligible number of cases and controls for each category. Moreover, they did not use the lowest cutoff point of $25(\mathrm{OH}) \mathrm{D}$ concentration as the reference, therefore, we transformed the OR and 95\% CI extracted from them into the lowest cut-off point as a reference, based on the method introduced by Hamling et al. [36]. The hazard ratios of the case-cohort study were deemed as OR. The summary OR $(95 \% \mathrm{CI})$ was $0.39(0.27,0.57)$ for the highest cut-off point as compared with the lowest cut-off point of $25(\mathrm{OH}) \mathrm{D}$ concentration. The $P$ value of Cochrane Q test was $<0.001$, and the $I^{2}$ statistics was $76.7 \%$, which indicated that the heterogeneity among the analyzed studies was significant.

\section{Subgroup, meta-regression, and sensitivity analysis}

Subgroup analysis and meta-regression are summarized in Table 3. Meta-regression was exerted to explore the heterogeneity among the subgroups. All categories of $25(\mathrm{OH}) \mathrm{D}$ concentration extracted from the 16 studies were included in this meta-regression. The results of the analysis revealed negative correlation between the serum $25(\mathrm{OH}) \mathrm{D}$ concentration and $\log$ OR of T1DM with statistical significance $\left(P_{\text {between }}\right.$ $<0.001$; Fig. 3). Latitude for each study was also considered, with the results showing positive correlation with statistical significance $\left(P_{\text {between }}=0.02\right.$; Fig. 4). Adjustment for gender indicated statistical significance $\left(P_{\text {between }}=0.001\right)$ between the subgroups. Nevertheless, the subgroups stratified by age, ethnicity, assay method for estimating 25(OH)D concentration, duration of T1DM, and adjustment of ethnicity showed no statistical significance between the subgroups in heterogeneity.
Sensitivity analysis was conducted to investigate which individual study with extreme OR influenced the pooled OR. For instance, if the study by Hamed et al. [22] with the smallest sample was omitted, the summary effects changed to summary OR $(95 \% \mathrm{CI}) 0.41(0.28,0.59)$. Moreover, if the case-cohort study and case-control study published by Jacobson et al. [28] with the relatively largest sample size were omitted, the summary effects changed to summary OR $(95 \%$ CI $) 0.36(0.27,0.48)$ and summary OR $(95 \% \mathrm{CI}) 0.36$ $(0.25,0.53)$, respectively. However, the summary effects were not influenced substantially.

\section{Dose-response meta-analysis}

Figure 5 displays the results of dose-response analysis. A total of 10 studies with 2223 cases and 2730 controls were involved in the dose-response meta-analysis. Studies by Bener et al. [21], Hamed et al. [22], Azab et al. [24], and Cadario et al. [27] were excluded from the dose-response meta-analysis, considering that they did not stratify the serum $25(\mathrm{OH}) \mathrm{D}$ concentration in not less than three categories. Similarly, the two studies by Jacobsen et al. [28] were also excluded because they did not provide the number of cases and controls for each category.

We noted an inverse nonlinear association between the serum $25(\mathrm{OH}) \mathrm{D}$ concentration and the T1DM risk (chisquare $=131.08, P<0.001)$, and the heterogeneity was insignificant $(Q=22.24, P=0.39)$ for both fixed and random models. The OR (95\% CI) of T1DM was 0.91 (0.90, 0.93 ) per $10 \mathrm{nmol} / \mathrm{L}$ increase in the $25(\mathrm{OH}) \mathrm{D}$ concentration. A ' $U$ '-shaped association was found. The risk of T1DM significantly descended with the $25(\mathrm{OH}) \mathrm{D}$ concentration ranging from 39 to $89 \mathrm{nmol} / \mathrm{L}$ with $\mathrm{OR}(95 \% \mathrm{CI})$ from 0.79 
Table 3 Subgroup analysis for risk of T1DM.

\begin{tabular}{|c|c|c|c|c|c|c|}
\hline \multirow[t]{2}{*}{ Subgroup } & \multirow[t]{2}{*}{ No. of studies } & \multicolumn{2}{|c|}{ Risk of T1DM ${ }^{a}$} & \multirow[t]{2}{*}{$\mathrm{I}^{2}, \%$} & \multirow[t]{2}{*}{$P_{\text {within }}{ }^{\mathrm{b}}$} & \multirow[t]{2}{*}{$P_{\text {between }}{ }^{\mathrm{c}}$} \\
\hline & & OR & $95 \% \mathrm{CI}$ & & & \\
\hline Overall & 16 & 0.39 & $(0.27,0.57)$ & $76.70 \%$ & & \\
\hline \multicolumn{7}{|l|}{ Age } \\
\hline Only children & 12 & 0.40 & $(0.24,0.64)$ & 81.1 & $<0.001$ & 0.77 \\
\hline Other & 4 & 0.36 & $(0.26,0.50)$ & 0.0 & 0.53 & \\
\hline \multicolumn{7}{|l|}{ Ethnicity } \\
\hline White & 2 & 0.42 & $(0.25,0.72)$ & 0.0 & 0.33 & 0.16 \\
\hline Yellow & 2 & 0.29 & $(0.19,0.45)$ & 0.0 & 0.65 & \\
\hline Mix & 6 & 0.65 & $(0.4,1.05)$ & 73.4 & 0.002 & \\
\hline \multicolumn{7}{|l|}{ Latitude, ${ }^{\circ} \mathrm{N}$} \\
\hline$\leq 30$ & 5 & 0.29 & $(0.16,0.54)$ & 55.3 & 0.06 & 0.02 \\
\hline $31-45$ & 9 & 0.35 & $(0.26,0.47)$ & 36.4 & 0.13 & \\
\hline$>45$ & 2 & 1.15 & $(0.85,1.57)$ & 0.0 & 0.75 & \\
\hline \multicolumn{7}{|c|}{ Categories of $25(\mathrm{OH}) \mathrm{D}, \mathrm{nmol} / \mathrm{L}$} \\
\hline$\leq 50$ & 1 & 0.67 & $(0.39,1.15)$ & NA & NA & $<0.001$ \\
\hline $50-75$ & 5 & 0.27 & $(0.18,0.41)$ & 16.8 & 0.31 & \\
\hline $75-100$ & 2 & 1.15 & $(0.85,1.57)$ & 0.0 & 0.75 & \\
\hline$>100$ & 8 & 0.33 & $(0.24,0.45)$ & 26.3 & 0.22 & \\
\hline \multicolumn{7}{|c|}{ Assay method of $25(\mathrm{OH}) \mathrm{D}$} \\
\hline RIA & 2 & 0.39 & $(0.17,0.89)$ & 68.5 & 0.08 & 0.10 \\
\hline HPLC & 3 & 0.24 & $(0.13,0.45)$ & 17.9 & 0.30 & \\
\hline CPBA & 1 & 0.03 & $(0.00,0.48)$ & NA & NA & \\
\hline CLIA & 3 & 0.38 & $(0.26,0.56)$ & 0.0 & 0.61 & \\
\hline ELISA & 4 & 0.27 & $(0.19,0.38)$ & 0.0 & 0.62 & \\
\hline LC-MS & 3 & 0.98 & $(0.68,1.42)$ & 33.6 & 0.22 & \\
\hline \multicolumn{7}{|c|}{ Duration of T1DM } \\
\hline$>1$ year & 3 & 0.25 & $(0.13,0.47)$ & 17.3 & 0.30 & 0.50 \\
\hline$<1$ year & 2 & 0.38 & $(0.16,0.89)$ & 0.0 & 0.64 & \\
\hline \multicolumn{7}{|c|}{ Adjustment for ethnicity } \\
\hline Yes & 6 & 0.40 & $(0.26,0.60)$ & 58.1 & 0.04 & 0.98 \\
\hline No & 10 & 0.38 & $(0.22,0.68)$ & 81.9 & $<0.001$ & \\
\hline \multicolumn{7}{|c|}{ Adjustment for gender } \\
\hline Yes & 11 & 0.31 & $(0.25,0.39)$ & 17.3 & 0.28 & 0.001 \\
\hline No & 5 & 0.80 & $(0.46,1.39)$ & 59.8 & 0.04 & \\
\hline
\end{tabular}

TIDM type 1 diabetes, $N$ number, OR odds ratio, 95\% CI 95\% confidential interval.

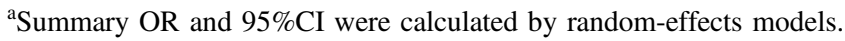

${ }^{\mathrm{b}} P_{\text {within }}$ was the $P$ value for heterogeneity within each subgroup.

${ }^{\mathrm{c}} P_{\text {between }}$ calculated by meta-regression was the $P$ value for heterogeneity between subgroups
$(0.61,1.02)$ to $0.31(0.25,0.39)$, trended stably when the 25 $(\mathrm{OH}) \mathrm{D}$ concentration reached $103-113 \mathrm{nmol} / \mathrm{L}$ with $\mathrm{OR}$ $(95 \% \mathrm{CI})$ around $0.28(0.22,0.35)$, and slightly ascended when the $25(\mathrm{OH}) \mathrm{D}$ concentration surpassed $150 \mathrm{nmol} / \mathrm{L}$ with OR 95\% CI and $0.34(0.25,0.45)$.

\section{Publication bias}

The funnel plot (Supplementary Material File) was asymmetrical and the Egger's test revealed $P=0.03$, suggesting that publication bias was significant among the studies. Nevertheless, the results did not fluctuate after a trim and fill test, indicating that the impact of the publication bias was probably modest.

\section{Discussion}

In this meta-analysis of 16 observational studies including 10,605 participants, a significant inverse association was 
Fig. 3 Meta-regression for all categories of $25(\mathrm{OH}) \mathrm{D}$ concentration and risk of T1DM.
Fig. 4 Meta-regression for latitude and risk of T1DM.
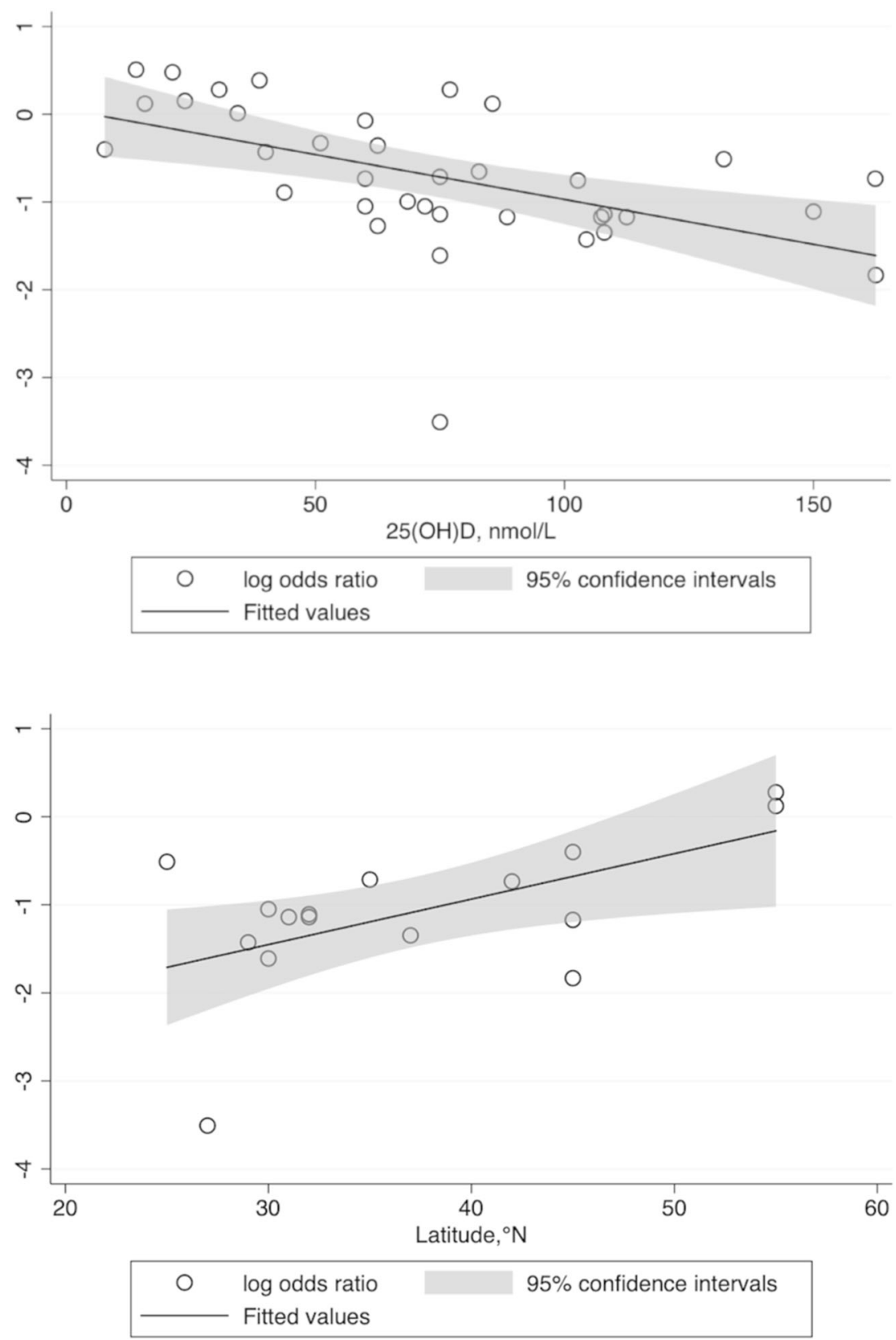

recorded between the highest versus the lowest circulating $25(\mathrm{OH}) \mathrm{D}$ concentration and the T1DM risk. This analysis demonstrated the role of vitamin $\mathrm{D}$ as a protective factor for T1DM, albeit the heterogeneity among the pooled studies was significant. In support, Shen et al. [37] reported that patients with T1DM showed a lower $25(\mathrm{OH}) \mathrm{D}$ concentration than controls in a meta-analysis of 12 studies including 3885 participants. Furthermore, Rak et al. [38] asserted that proper vitamin D supplementation could reduce the incidence and complications of T1DM.

Subgroup analysis along with meta-regression was applied to explore the source of heterogeneity. We recognized a positive association between the latitude of patient location and risk of T1DM, which suggests that individuals living in high latitude may be predisposed to T1DM. Weng et al. [4] also reported that the incidence of T1DM among children aged $<14$ years was strongly correlated with the latitude, with the rates being higher in the north of China than in the south. Kimlin et al. [39] emphasized that the latitude strongly influences the serum $25(\mathrm{OH}) \mathrm{D}$ concentration among participants across a broad latitude range in the southern hemisphere. Mohr et al. [40] identified that the incidence of T1DM tended to be higher at higher latitudes in both the hemispheres, because residents living near the Equator obtained adequate vitamin $\mathrm{D}$ due to the strong solar ultraviolet 
Fig. 5 Dose-response analysis of serum $25(\mathrm{OH}) \mathrm{D}$

concentration and risk of T1DM.

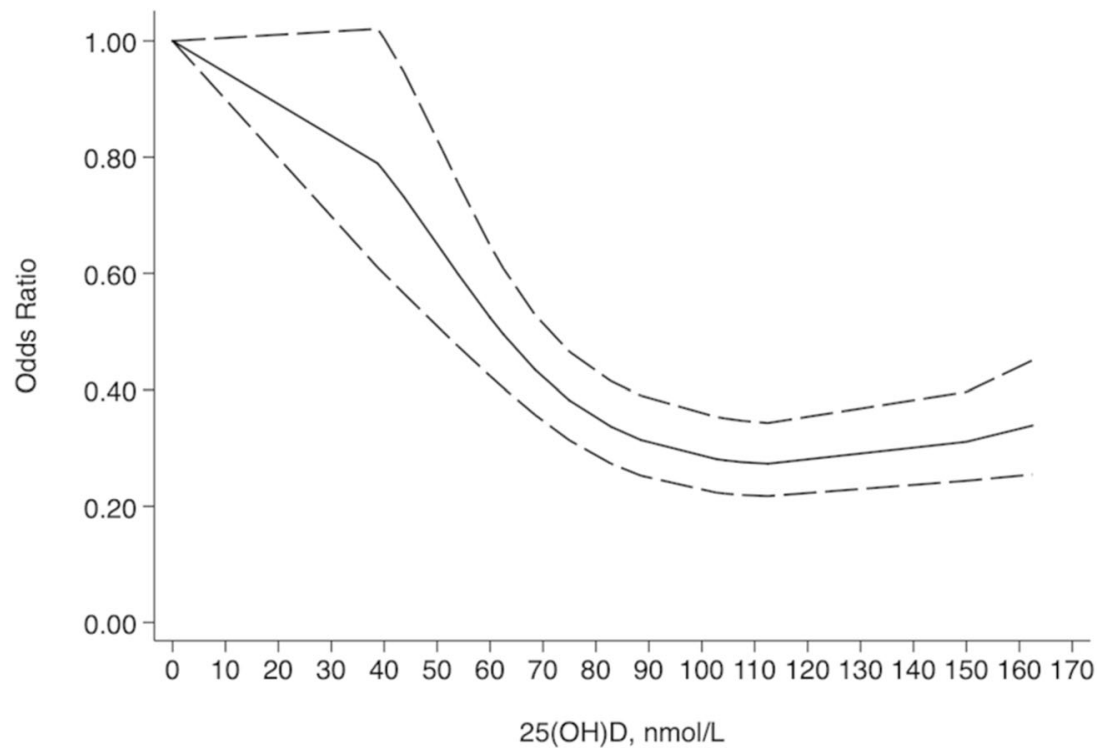

B irradiance available there. More consistent studies indicated that the latitude influences the serum $25(\mathrm{OH}) \mathrm{D}$ concentration, which in turn affects the incidence rate of T1DM.

Adjustment for gender was identified as a potential source of heterogeneity. A previous study EURODIAB found that the incidence of T1DM was nearly the same between both the genders of children [41]. However, Weng et al. [4] discovered that the incidence of T1DM was higher among girls under the age of 14 years. Thus, adjustment for gender among individual studies needs to be carefully evaluated in the future.

We also identified that the association was undeviating and did not diverge appreciably after stratifying by age, ethnicity, assay method for estimating the 25(OH)D concentration, duration of T1DM, and adjustment for ethnicity. Shen et al. [37] found that the $25(\mathrm{OH}) \mathrm{D}$ concentration was lower in patients with T1DM than in controls in a subgroup population aged $\leq 14$ years. High-performance liquid chromatography (HPLC) was considered as the golden standard assay method to determine the $25(\mathrm{OH}) \mathrm{D}$ concentration [42]. Al-Haddad et al. [43] emphasized that chemiluminescence micro-particle immunoassay overestimates vitamin $\mathrm{D}$ deficiency in comparison to HPLC. These reports suggest that physicians should select the assay method for estimating the $25(\mathrm{OH}) \mathrm{D}$ concentration extremely cautiously. However, in our study, the pooled OR of T1DM did not differ by the assay methods. This difference from other reports may be attributed to statistical fluctuation in the small sample size in this study, highlighting the need for further studies to clarify the source of heterogeneity.

Notably, we observed a significant inverse correlation between the circulating $25(\mathrm{OH}) \mathrm{D}$ concentration and the risk of T1DM and developed a robust database supporting the dose-response curve. To the best of our knowledge, no previous studies have addressed the quantitative association between serum $25(\mathrm{OH}) \mathrm{D}$ concentration of $100-150 \mathrm{nmol} / \mathrm{L}$ to the significantly lower risk of T1DM. Functionally, sufficient serum $25(\mathrm{OH}) \mathrm{D}$ concentration can preserve the activity of residual pancreatic $\beta$-cells and insulin secretion [44]. Meanwhile, a past study reported that the serum 25 $(\mathrm{OH}) \mathrm{D}$ concentration was negatively associated with insulin resistance in patients with T1DM [45]. Children with T1DM have also been reported to have lower $25(\mathrm{OH}) \mathrm{D}$ concentration than healthy children [5]. Low 25(OH)D concentration may be associated with lower insulin concentration in hepatic portal vein inhibiting the 25hydroxylase activity. Although intraperitoneal insulin increased the $25(\mathrm{OH}) \mathrm{D}$ concentration in the hepatic vein, long-term intraperitoneal insulin treatment did not affect the $25(\mathrm{OH}) \mathrm{D}$ concentration when compared with subcutaneous insulin treatment in patients with T1DM [46]. Moreover, from the perspective of the Nutrition Society, the guidelines for vitamin D supplementation and assay standard of 25 $(\mathrm{OH}) \mathrm{D}$ concentration are in a standstill period [47]. The nutritional guideline from Netherlands [48] suggests that a serum $25(\mathrm{OH}) \mathrm{D}$ concentration of $>30 \mathrm{nmol} / \mathrm{L}$ is sufficient for individuals except for adults above the age of 70 years whose target serum $25(\mathrm{OH}) \mathrm{D}$ concentration is beyond $50 \mathrm{nmol} / \mathrm{L}$. Besides, the Scientific Advisory Committee on Nutrition [49] and German Nutrition Society [50] advocate that serum $25(\mathrm{OH}) \mathrm{D}$ concentration maintains at least $50 \mathrm{nmol} / \mathrm{L}$ for generally healthy individuals. However, the German vitamin D intake recommendations (200-800 IU per day) had no effect on improving the serum $25(\mathrm{OH}) \mathrm{D}$ concentration of infants and adolescents in the latest report, which means they need to revise the guideline [51]. The endocrine guideline from the Middle East and North Africa 
[52] also recommends a serum 25(OH)D concentration of $>50 \mathrm{nmol} / \mathrm{L}$ is sufficient for generally healthy individuals, while the Endocrine Society [53] supports serum 25(OH)D concentration of $>75 \mathrm{nmol} / \mathrm{L}$ for individuals in all ages including pregnancy and lactating. Other guidelines from Australia [54] uphold that serum 25(OH)D concentration of $>50 \mathrm{nmol} / \mathrm{L}$ is sufficient for pregnant women and the National Osteoporosis Foundation [55] and the bone-centric guidelines [6] support serum $25(\mathrm{OH}) \mathrm{D}$ concentration of $>50 \mathrm{nmol} / \mathrm{L}$ is adequate for nearly the entire population, while American Geriatrics Society [56] proposes serum 25 $(\mathrm{OH}) \mathrm{D}$ concentration of $>75 \mathrm{nmol} / \mathrm{L}$ is sufficient for adults aged over 70 years. Moreover, the guidelines focused on the pleiotropic effects of vitamin D recommended a target 25 $(\mathrm{OH}) \mathrm{D}$ concentration of $75 \mathrm{nmol} / \mathrm{L}$ [6]. Thus, guidelines for target serum $25(\mathrm{OH}) \mathrm{D}$ concentration from nutritional and endocrine fields differ, probably because they focused on different populations and geographic locations. Interestingly, we found that most guidelines targeted adults aged beyond 70 years set their goal for vitamin D sufficiency is $75 \mathrm{nmol} / \mathrm{L}$ which is higher than others because the elder is more likely to fall and fracture. For infants, children, pregnant or lactating women, most guidelines agree with optimal serum $25(\mathrm{OH}) \mathrm{D}$ concentration of $>50 \mathrm{nmol} / \mathrm{L}$ or depending on their health condition. Notably, most European vitamin $\mathrm{D}$ researchers and organizations considered serum $25(\mathrm{OH}) \mathrm{D}$ concentration $50 \mathrm{nmol} / \mathrm{L}$ to be necessary, while in the United States, they recommend $75 \mathrm{nmol} / \mathrm{L}$ and some others are calling for $100-150 \mathrm{nmol} / \mathrm{L}$. The difference between the recommendations from the two continents may be due to the greater reliance on RCTs by European researches. Unfortunately, most RCTs up to now were poorly designed and conducted since they were based on guidelines for drugs, not nutrients [57]. So, the RCT designers should pay more attention to serum 25(OH)D concentration, not vitamin D dose [58]. What is more, the relationship between serum 25(OH)D concentration and health outcomes may vary for different diseases [6]. The viewpoints from the Scientific Advisory Committee on Nutrition [49], Middle East and North Africa [52] and the Endocrine Society [53] espouse that vitamin D is a protective factor for diabetes, while others show uncertainty. This meta-analysis has explored the connection between them.

Our meta-analysis identified contradicting results with those from past RCTs. The daily supplementation of vitamin D differs across countries and organizations. For children under 18 years, the recommendation vitamin $\mathrm{D}$ dose was 200-1000 IU [59]. And it depended on age, health status, body weight, and race that the daily vitamin D dose recommendation ranged from 400-2000 IU [6]. Therefore, no consensus has yet been reached regarding the ideal daily supplementation concentration. Shih et al. [60] conducted a randomized prospective crossover study with 25 adolescents with T1DM and found that even a 6-month-long vitamin D repletion did not affect the status of glycemia or inflammatory biomarkers. Similarly, Sharma et al. [61] reported that the administration of oral vitamin D therapy once a month for 6 months led to no significant decrease in the $\mathrm{HbAlc}$ status and in the exogenous insulin requirements in their double-blinded RCT including 52 children. Recently, Kadhim et al. [62] conducted an RCT, wherein they provided 50 newly diagnosed pediatric patients and 25 healthy children with a daily vitamin D3 dosage of 2000 IU for a period of 90 days; the authors recorded significantly positive immune response and an increase in the serum 25 $(\mathrm{OH}) \mathrm{D}$ concentration for the patients. Previous RCTs were majorly conducted in participants without insufficient serum 25(OH)D concentration. Most meta-analyses resulting from RCT did not reveal that the vitamin D supplementation benefited health, which contradicts the observational studies, which claim that insufficient serum 25(OH)D concentration has adverse ill effects on health [63]. Owing to the fixed vitamin $\mathrm{D}$ dose in the interventional studies, the circulating $25(\mathrm{OH}) \mathrm{D}$ concentration may have fluctuated in a narrow range, which could not build a substantial cause-effect association between vitamin D supplementation and positive health outcomes. Our meta-analysis suggests that, in the future, studies should set a target of serum $25(\mathrm{OH}) \mathrm{D}$ concentration when supplying vitamin $\mathrm{D}$ for yielding stable results.

Notwithstanding, we noted some limitations in our study. For instance, most of the included articles were case-control studies, which is not a relatively robust study design toward confirming a causal relationship. As compared with studies that record data in the real time, case-control studies have a greater probability of recall bias. In addition, this metaanalysis was based on observational studies that were generally not considered to be able to demonstrate causality between serum $25(\mathrm{OH}) \mathrm{D}$ concentration and T1DM risk [64]. However, according to Hill's criteria for causality, we disclosed the dose-response curve that cast a new light on the possible causality that low serum $25(\mathrm{OH}) \mathrm{D}$ concentration had adverse effects on T1DM [65, 66].

\section{Conclusions}

In conclusion, through our dose-response meta-analysis enlisting 16 studies, we demonstrated a significant inverse association between the $25(\mathrm{OH}) \mathrm{D}$ concentration in circulation and the risk of T1DM. The resultant dose-response relationship also provided a broad $25(\mathrm{OH}) \mathrm{D}$ spectrum. We suggest the necessity for further studies focusing on the molecular mechanism underlying this association. In clinical relevance, optimized and well-designed RCT are 
necessary to yield greater insights to the benefits and safety of vitamin $\mathrm{D}$ supplementation in preventing the risk of developing T1DM.

Supplementary information is available at EJCN's website.

Author contributions $\mathrm{YH}$ conceived and designed this study. $\mathrm{YH}$ and YJ performed the data extraction and quality assessment independently. YH and QX summarized the data. YH drafted the first manuscript revised by GS and XX. AS edited the final manuscript. YH and AS contributed equally to this paper. All authors read and approved the final manuscript.

\section{Compliance with ethical standards}

Conflict of interest All authors declare that they have no conflict of interest.

Publisher's note Springer Nature remains neutral with regard to jurisdictional claims in published maps and institutional affiliations.

Open Access This article is licensed under a Creative Commons Attribution 4.0 International License, which permits use, sharing, adaptation, distribution and reproduction in any medium or format, as long as you give appropriate credit to the original author(s) and the source, provide a link to the Creative Commons license, and indicate if changes were made. The images or other third party material in this article are included in the article's Creative Commons license, unless indicated otherwise in a credit line to the material. If material is not included in the article's Creative Commons license and your intended use is not permitted by statutory regulation or exceeds the permitted use, you will need to obtain permission directly from the copyright holder. To view a copy of this license, visit http://creativecommons. org/licenses/by/4.0/.

\section{References}

1. Norris JM, Johnson RK, Stene LC. Type 1 diabetes-early life origins and changing epidemiology. Lancet Diabetes Endocrinol. 2020;8:226-38.

2. Divers J, Mayer-Davis EJ, Lawrence JM, Isom S, Dabelea D, Dolan L, et al. Trends in incidence of type 1 and type 2 diabetes among youths - selected counties and indian reservations, United States, 2002-2015. MMWR Morb Mortal Wkly Rep. 2020;69: $161-5$.

3. Patterson CC, Harjutsalo V, Rosenbauer J, Neu A, Cinek O, Skrivarhaug T, et al. Trends and cyclical variation in the incidence of childhood type 1 diabetes in 26 European centres in the 25 year period 1989-2013: a multicentre prospective registration study. Diabetologia. 2019;62:408-17.

4. Weng J, Zhou Z, Guo L, Zhu D, Ji L, Luo X, et al. Incidence of type 1 diabetes in China, 2010-13: population based study. BMJ. 2018;360:j5295.

5. Tjahjono HA. Vitamin D and Type 1 diabetes mellitus in children. Horm Res Paediatr. 2019;91:645-6.

6. Pludowski P, Holick MF, Grant WB, Konstantynowicz J, Mascarenhas MR, Haq A, et al. Vitamin D supplementation guidelines. J Steroid Biochem Mol Biol. 2018;175:125-35.

7. Murdaca G, Tonacci A, Negrini S, Greco M, Borro M, Puppo F, et al. Emerging role of vitamin D in autoimmune diseases: an update on evidence and therapeutic implications. Autoimmun Rev. 2019;18:102350.
8. Hypponen E, Laara E, Reunanen A, Jarvelin MR, Virtanen SM. Intake of vitamin $\mathrm{D}$ and risk of type 1 diabetes: a birth-cohort study. Lancet. 2001;358:1500-3.

9. Alkharashi NA. Estimation of vitamin D deficiency prevalence among Saudi children in Armed Forces Hospital and Riyadh Care Hospital in Riyadh, Kingdom of Saudi Arabia and its relation to type 1 diabetes mellitus. Saudi Med J. 2019;40: 1290-3.

10. Norris JM, Lee H-S, Frederiksen B, Erlund I, Uusitalo U, Yang J, et al. Plasma 25-hydroxyvitamin D concentration and risk of islet autoimmunity. Diabetes 2018;67:146-54.

11. Simpson M, Brady H, Yin X, Seifert J, Barriga K, Hoffman M, et al. No association of vitamin D intake or 25-hydroxyvitamin D levels in childhood with risk of islet autoimmunity and type 1 diabetes: the Diabetes Autoimmunity Study in the Young (DAISY). Diabetologia. 2011;54:2779-88.

12. Reinert-Hartwall L, Honkanen J, Härkönen T, Ilonen J, Simell O, Peet A, et al. No association between vitamin D and $\beta$-cell autoimmunity in Finnish and Estonian children. Diabetes/Metab Res Rev. 2014;30:749-60.

13. Myśliwec A, Skalska M, Knechtle B, Nikolaidis PT, Rosemann T, Szmigiero-Kawko M, et al. Acute responses to low and high intensity exercise in type 1 diabetic adolescents in relation to their level of serum 25(OH)D. Nutrients. 2020;12:454.

14. Wells G, Shea B, O'connell D, Peterson J, Welch V, Losos M, et al. The Newcastle-Ottawa Scale (NOS) for assessing the quality of nonrandomised studies in meta-analyses [Internet]. Ottawa Hospital Research Institute. Available from: http://www.ohri.ca/ programs/clinical_epidemiology/oxford.asp. 2014.

15. DerSimonian R, Laird N. Meta-analysis in clinical trials. Control Clin Trials 1986;7:177-88.

16. Higgins JP, Thompson SG. Quantifying heterogeneity in a metaanalysis. Stat Med. 2002;21:1539-58.

17. Egger M, Davey Smith G, Schneider M, Minder C. Bias in metaanalysis detected by a simple, graphical test. BMJ. 1997;315:629-34.

18. Duval S, Tweedie R. Trim and fill: a simple funnel-plot-based method of testing and adjusting for publication bias in metaanalysis. Biometrics. 2000;56:455-63.

19. Greenland S, Longnecker MP. Methods for trend estimation from summarized dose-response data, with applications to metaanalysis. Am J Epidemiol. 1992;135:1301-9.

20. Orsini N, Bellocco R, Greenland S. Generalized least squares for trend estimation of summarized dose-response data. Stata J. 2006;6:40-57.

21. Bener A, Alsaied A, Al-Ali M, Hassan AS, Basha B, Al-Kubaisi A, et al. Impact of lifestyle and dietary habits on hypovitaminosis $\mathrm{D}$ in type 1 diabetes mellitus and healthy children from Qatar, a sun-rich country. Ann Nutr Metab. 2008;53:215-22.

22. Hamed EA, Abu Faddan NH, Adb Elhafeez HA, Sayed D. Parathormone-25(OH)-vitamin D axis and bone status in children and adolescents with type 1 diabetes mellitus. Pediatr Diabetes. 2011;12:536-46.

23. Ghandchi Z, Neyestani TR, Yaraghi AA, Eshraghian MR, Gharavi A, Shariatzadeh N, et al. Vitamin D status and the predictors of circulating T helper 1-type immunoglobulin levels in Iranian subjects with type 1 diabetes and their siblings: a case-control study. J Hum Nutr dietetics: Off J Br Dietetic Assoc. 2012;25:365-72.

24. Azab SFA, Saleh SH, Elsaeed WF, Abdelsalam SM, Ali AA, Esh AMH. Vitamin D status in diabetic Egyptian children and adolescents: a case-control study. Italian J Pediatr. 2013;39:73.

25. Abd-Allah SH, Pasha HF, Hagrass HA, Alghobashy AA. Vitamin D status and vitamin D receptor gene polymorphisms and susceptibility to type 1 diabetes in Egyptian children. Gene. 2014;536:430-4. 
26. Franchi B, Piazza M, Sandri M, Mazzei F, Maffeis C, Boner AL. Vitamin $\mathrm{D}$ at the onset of type 1 diabetes in Italian children. Eur $\mathbf{J}$ Pediatrics. 2014;173:477-82.

27. Cadario F, Savastio S, Pagliardini V, Bagnati M, Vidali M, Cerutti $\mathrm{F}$, et al. Vitamin $\mathrm{D}$ levels at birth and risk of type 1 diabetes in childhood: a case-control study. Acta Diabetologica. 2015;52:1077-81.

28. Jacobsen R, Thorsen SU, Cohen AS, Lundqvist M, Frederiksen P, Pipper CB, et al. Neonatal vitamin D status is not associated with later risk of type 1 diabetes: results from two large Danish population-based studies. Diabetologia. 2016;59:1871-81.

29. Rasoul MA, Al-Mahdi M, Al-Kandari H, Dhaunsi GS, Haider MZ. Low serum vitamin-D status is associated with high prevalence and early onset of type-1 diabetes mellitus in Kuwaiti children. BMC Pediatr. 2016;16:95.

30. Bae KN, Nam HK, Rhie YJ, Song DJ, Lee KH. Low levels of 25hydroxyvitamin $\mathrm{D}$ in children and adolescents with type 1 diabetes mellitus: A single center experience. Ann Pediatr Endocrinol Metab. 2018;23:21-7.

31. Federico G, Genoni A, Puggioni A, Saba A, Gallo D, Randazzo E, et al. Vitamin D status, enterovirus infection, and type 1 diabetes in Italian children/adolescents. Pediatr Diabetes. 2018;19:923-9.

32. Liu C, Wang J, Wan Y, Xia X, Pan J, Gu W, et al. Serum vitamin $\mathrm{D}$ deficiency in children and adolescents is associated with type 1 diabetes mellitus. Endocr Connect. 2018;7:1275-9.

33. Gorham ED, Garland CF, Burgi AA, Mohr SB, Zeng K, Hofflich $\mathrm{H}$, et al. Lower prediagnostic serum 25-hydroxyvitamin D concentration is associated with higher risk of insulin-requiring diabetes:a nested case-control study. Diabetologia. 2012;55:3224-7.

34. Munger KL, Levin LI, Massa J, Horst R, Orban T, Ascherio A. Preclinical serum 25-hydroxyvitamin $\mathrm{D}$ levels and risk of type 1 diabetes in a cohort of US military personnel. Am J Epidemiol. 2013;177:411-9.

35. Borkar VV, Devidayal VS, Bhalla AK. Low levels of vitamin D in North Indian children with newly diagnosed type 1 diabetes. Pediatr Diabetes. 2010;11:345-50.

36. Hamling J, Lee $P$, Weitkunat $R$, Ambuhl M. Facilitating metaanalyses by deriving relative effect and precision estimates for alternative comparisons from a set of estimates presented by exposure level or disease category. Stat Med. 2008;27:954-70.

37. Shen L, Zhuang Q-S, Ji H-F. Assessment of vitamin D levels in type 1 and type 2 diabetes patients: results from metaanalysis. Mol Nutr Food Res. 2016;60:1059-67.

38. Rak K, Bronkowska M. Immunomodulatory effect of vitamin D and its potential role in the prevention and treatment of type 1 diabetes mellitus-a narrative review. Molecules. 2018;24:53.

39. Kimlin MG, Lucas RM, Harrison SL, van der Mei I, Armstrong BK, Whiteman DC, et al. The contributions of solar ultraviolet radiation exposure and other determinants to serum 25hydroxyvitamin D concentrations in Australian adults: the AusD Study. Am J Epidemiol. 2014;179:864-74.

40. Mohr SB, Garland CF, Gorham ED, Garland FC. The association between ultraviolet B irradiance, vitamin D status and incidence rates of type 1 diabetes in 51 regions worldwide. Diabetologia. 2008;51:1391-8.

41. Patterson CC, Dahlquist GG, Gyurus E, Green A, Soltesz G, Group ES. Incidence trends for childhood type 1 diabetes in Europe during 1989-2003 and predicted new cases 2005-20: a multicentre prospective registration study. Lancet. 2009;373:2027-33.

42. Hollis BW. Editorial: The determination of circulating 25hydroxyvitamin D: no easy task. J Clin Endocrinol Metab. 2004;89:3149-51.

43. Al-Haddad FA, Rajab MH, Al-Qallaf SM, Musaiger AO, Hart $\mathrm{KH}$. Assessment of vitamin D levels in newly diagnosed children with type 1 diabetes mellitus comparing two methods of measurement: a facility's experience in the Middle Eastern country of Bahrain. Diabetes, Metab Syndr Obes: Targets Ther. 2016;9:11-6.

44. Habibian N, Amoli MM, Abbasi F, Rabbani A, Alipour A, Sayarifard F, et al. Role of vitamin D and vitamin $\mathrm{D}$ receptor gene polymorphisms on residual beta cell function in children with type 1 diabetes mellitus. Pharmacol Rep. 2019;71:282-8.

45. Kamiński M, Uruska A, Rogowicz-Frontczak A, Lipski D, Niedźwiecki P, Różańska O, et al. Insulin resistance in adults with type 1 diabetes is associated with lower vitamin D serum concentration. Exp Clin Endocrinol Diabetes. 2019. https://doi.org/ 10.1055/a-0895-5166.

46. Van Dijk PR, Logtenberg SJJ, Waanders F, Groenier KH, Van Goor H, Kleefstra N, et al. Route of insulin does not influence 25hydroxyvitamin $\mathrm{D}$ concentrations in type 1 diabetes: a brief report. J Endocr Soc. 2019;3:1541-4.

47. Sempos CT, Binkley N. 25-hydroxyvitamin D assay standardisation and vitamin D guidelines paralysis. Public Health Nutr. 2020;23:1153-64.

48. Health Council of the Netherlands. Evaluation of the nutritional standards for vitamin D [Internet]. Available from: https://www. gezondheidsraad.nl/documenten/adviezen/2012/09/26/evaluatievan-de-voedingsnormen-voor-vitamine-d. 2012.

49. The Scientific Advisory Committee on Nutrition. Ultraviolet Radiation, Vitamin D and Health Report of the independent Advisory Group on Non-ionising Radiation [Internet]. Available from: https://assets.publishing.service.gov.uk/government/uploa ds/system/uploads/attachment_data/file/620184/UV_Radiation_ Vitamin_D__Health.pdf. 2017.

50. German Nutrition Society. New reference values for vitamin D. Ann Nutr Metab. 2012;60:241-6.

51. Kunz C, Hower J, Knoll A, Ritzenthaler KL, Lamberti T. No improvement in vitamin D status in German infants and adolescents between 2009 and 2014 despite public recommendations to increase vitamin D intake in 2012. Eur J Nutr. 2019;58:1711-22.

52. Chakhtoura M, Rahme M, Chamoun N, El-Hajj, Fuleihan G. Vitamin D in the Middle East and North Africa. Bone Rep. 2018;8:135-46.

53. Holick MF, Binkley NC, Bischoff-Ferrari HA, Gordon CM, Hanley DA, Heaney RP, et al. Evaluation, treatment, and prevention of vitamin D deficiency: an Endocrine Society clinical practice guideline. J Clin Endocrinol Metabol. 2011;96:1911-30.

54. Homer CS, Oats J, Middleton P, Ramson J, Diplock S. Updated clinical practice guidelines on pregnancy care. Med J Aust. 2018;209:409-12.

55. Aspray TJ, Bowring C, Fraser W, Gittoes N, Javaid MK, Macdonald $\mathrm{H}$, et al. National Osteoporosis Society vitamin $\mathrm{D}$ guideline summary. Age Ageing. 2014;43:592-5.

56. American Geriatrics Society. Recommendations abstracted from the American Geriatrics Society Consensus Statement on vitamin D for prevention of falls and their consequences. J Am Geriatr Soc. 2014;62:147-52.

57. Heaney RP. Guidelines for optimizing design and analysis of clinical studies of nutrient effects. Nutr Rev. 2014;72:48-54.

58. Grant WB, Boucher BJ, Bhattoa HP, Lahore H. Why vitamin D clinical trials should be based on 25-hydroxyvitamin D concentrations. J Steroid Biochem Mol Biol. 2018;177:266-9.

59. Bouillon R. Comparative analysis of nutritional guidelines for vitamin D. Nat Rev Endocrinol. 2017;13:466-79.

60. Shih EM, Mittelman S, Pitukcheewanont P, Azen CG, Monzavi R. Effects of vitamin D repletion on glycemic control and inflammatory cytokines in adolescents with type 1 diabetes. Pediatr Diabetes. 2016;17:36-43.

61. Sharma S, Biswal N, Bethou A, Rajappa M, Kumar S, Vinayagam V. Does vitamin D supplementation improve glycaemic control in 
children with type 1 diabetes mellitus? - a randomized controlled trial. J Clin Diagn Res. 2017;11:SC15-SC7.

62. Kadhim KA, Nafea LT, Fawzi HA, Hameed EA, Gasim GA. Assessment of vitamin d therapy effect on inflammatory markers in pediatric patients with type i diabetic. Asian J Pharm Clin Res. 2018;11:552-4.

63. Rejnmark L, Bislev LS, Cashman KD, Eiriksdottir G, Gaksch M, Grubler M, et al. Non-skeletal health effects of vitamin D supplementation: a systematic review on findings from meta-analyses summarizing trial data. PLoS One. 2017;12:e0180512.
64. Maretzke F, Bechthold A, Egert S, Ernst JB, Melo van Lent D, Pilz S, et al. Role of vitamin D in preventing and treating selected extraskeletal diseases-an umbrella review. Nutrients. 2020;12:969.

65. Hill AB. The environment and disease: association or causation? Proc R Soc Med. 1965;58:295-300.

66. Altieri B, Grant WB, Della Casa S, Orio F, Pontecorvi A, Colao A, et al. Vitamin D and pancreas: The role of sunshine vitamin in the pathogenesis of diabetes mellitus and pancreatic cancer. Crit Rev Food Sci Nutr. 2017;57:3472-88. 